\title{
ALTERNATIVE FOUNDATION DESIGN FOR TEMPORARY HOUSING UNITS
}

\author{
Omar S. Thomas ${ }^{1 *}$, Georgeann Henry ${ }^{2}$, Kordel Bishop ${ }^{3}$, Kymani Francis $^{4}$ and Ajene Binns ${ }^{5}$ \\ 1,2,3,4,5 Faculty of Engineering, The University of the West Indies, Mona Campus, Jamaica \\ ${ }^{1}$ Email: omar.thomas@uwimona.edu.jm *(Corresponding author) \\ ${ }^{2}$ Email: george.ann.h1997@gmail.com \\ ${ }^{3}$ Email: kordelbishop@yahoo.com \\ ${ }^{4}$ Email: kymanifrancis1@gmail.com \\ ${ }^{5}$ Email: ajene binns@gmail.com
}

\begin{abstract}
The Food for the Poor provides hundreds of thousands of temporary housing in the Americas and the Caribbean for persons in need of a shelter. These temporary houses provide a space in which many persons can live. Although these spaces are meant to be temporary, in many cases due to the lack of financial wherewithal, these temporary houses serve as a medium to long-term housing for those who receive them. The topographical and geotechnical environment in which these houses are built not only vary across the Americas and the Caribbean but varies within a single country. This study analyses the current foundation designs used by Food for the Poor in the country of Jamaica, taking into consideration Jamaica's unique hilly terrain and geotechnical environment. The study makes recommendations for the use of alternative foundation designs that are still economical for construction and are better when considering the life cycle cost of these structures. The use of bamboo as a reinforcement in concrete for the foundation design is also analysed and compared against the traditional reinforced concrete and mass concrete designs. The results demonstrate that when bamboo is used as a reinforcement with concrete it has an increased flexural strength, but still do not exceed the flexural strength of traditional reinforced concrete, that utilizes steel reinforcement.
\end{abstract}

Keywords: Bamboo reinforcement, Bamboo tensile strength, Temporary housing, Alternative reinforcement.

\section{https://doi.org/10.47412/ZSKL3861}

\section{Introduction}

This study involves a comparative study of types of materials that can provide a more sustainable type of reinforcement in the foundations of the temporary houses constructed by The Food for the Poor (FFP) Organisation. Currently, no reinforcement is being placed in the raft (slab on grade) foundation structure of the standard temporary timber houses provided in Jamaica through the FFP. The FFP is desirous of looking at options in improving the sustainability of the foundations without having a significant additional cost to the construction of the overall structure of the temporary housing. This study investigates the use of Bamboo as reinforcing material in concrete foundations. Extensive research has been done on the structural use of bamboo [1, 2, 3, 4, 5, 6, 7, $8,9]$. Bamboo has a long and established tradition as a building material $[1,2,4]$. It is used widely for many forms of construction, such as bridges, scaffoldings and houses [1, 4]. The U.S Naval Civil Engineering Lavatory published a journal about the bamboo reinforcement concrete in 1964 
which highlighted the feasibility of it being used as reinforcement in concrete [2]. Ultimate strength design procedures that were modified to take into account the characteristics of the bamboo reinforcement were used to estimate the ultimate load carrying capacity of precast concrete elements with bamboo reinforcing [2]. This study also investigated the traditional use of welded wire mesh as a form of reinforcement. The welded wire mesh is made from high yield strength steel wire by welding machines. For uniformity, the welded wire mesh is manufactured into flat sheets of mesh. This wire mesh provides proper distribution of tensile strength throughout the concrete in which it is placed. To study the alternative materials, concrete compressive tests were conducted on six cylindrical specimens of dimensions 4 inches (dia.) x 8 inches (height). Tests were also conducted on nine beam specimens, each having the dimensions 5 inches (width) x 6 inches (height) x 20 inches (length). Three specimens were doubly reinforced using bamboo strips coated in marine varnish, three specimens were reinforced with a section of wire mesh, and three specimens had no reinforcement (pure concrete). Beams were tested until failure using the three-point test and compared to conclude the most suitable alternative.

\section{Methodology}

The concrete was prepared manually using a 1:2:4 mix design. Formwork of dimensions 5" x 6" x 20" were created using $1 / 2$ inch plyboard, screws and sealant. The forms were lubricated with oilbefore the placement of the concrete. The concrete samples were tested on the 30th and 31st day after it was poured to closely represent its $28^{\text {th }}$ day design strength. The following are some of the procedural application taken in this study:

Procedural application:

- Curing: The bamboo was cut and allowed to dry for a week before using.

- Waterproof Coatings: The bamboo splints were coated with a marine environmental varnish to reduce swelling when in contact with the concrete and to help bonding between bamboo and concrete.

- Placement of bamboo: The bamboo strips were placed $1 / 2$ inch from the sides of the beams and 1 inch from the bottom before placing the concrete. The strips were secured in the formwork using wire, before placing the concrete.

- Mix design: A 1:2:4 mix design was used in making the concrete, which represents a M15 grade concrete. This design was chosen to approximate the mix design used in the field. The design was mixed manually, as typically done on majority of the FFP construction sites.

- Placement of Wire Mesh: A 18 inch by 4 inch wire mesh was placed $1 / 2$ inch from the sides of the beams and 1 inch from the bottom before placing the concrete. The wire mesh was secured in the formwork using wire, before placing the concrete.

The test set-up is shown in Fig. 1. Fig. 2 is a schematic diagram of the testing set-up for the bamboo reinforced samples with the relevant dimensions. The beams reinforced with the wired-mesh is similar, except, the mesh is positioned in the beam such that there is one longitudinal strand in the centre of the beam with a cover of 1 inch to the bottom surface. 


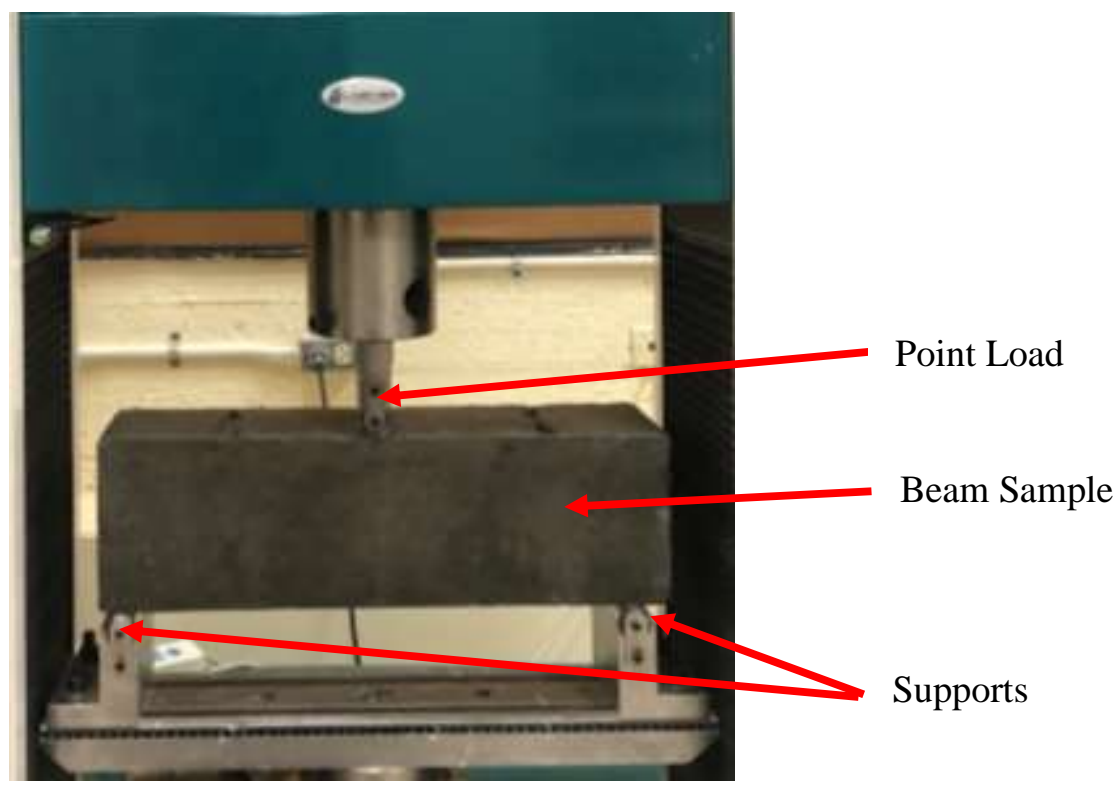

Figure 1: Three-point bending test set-up of beam samples in the Universal Testing Machine (UTM)

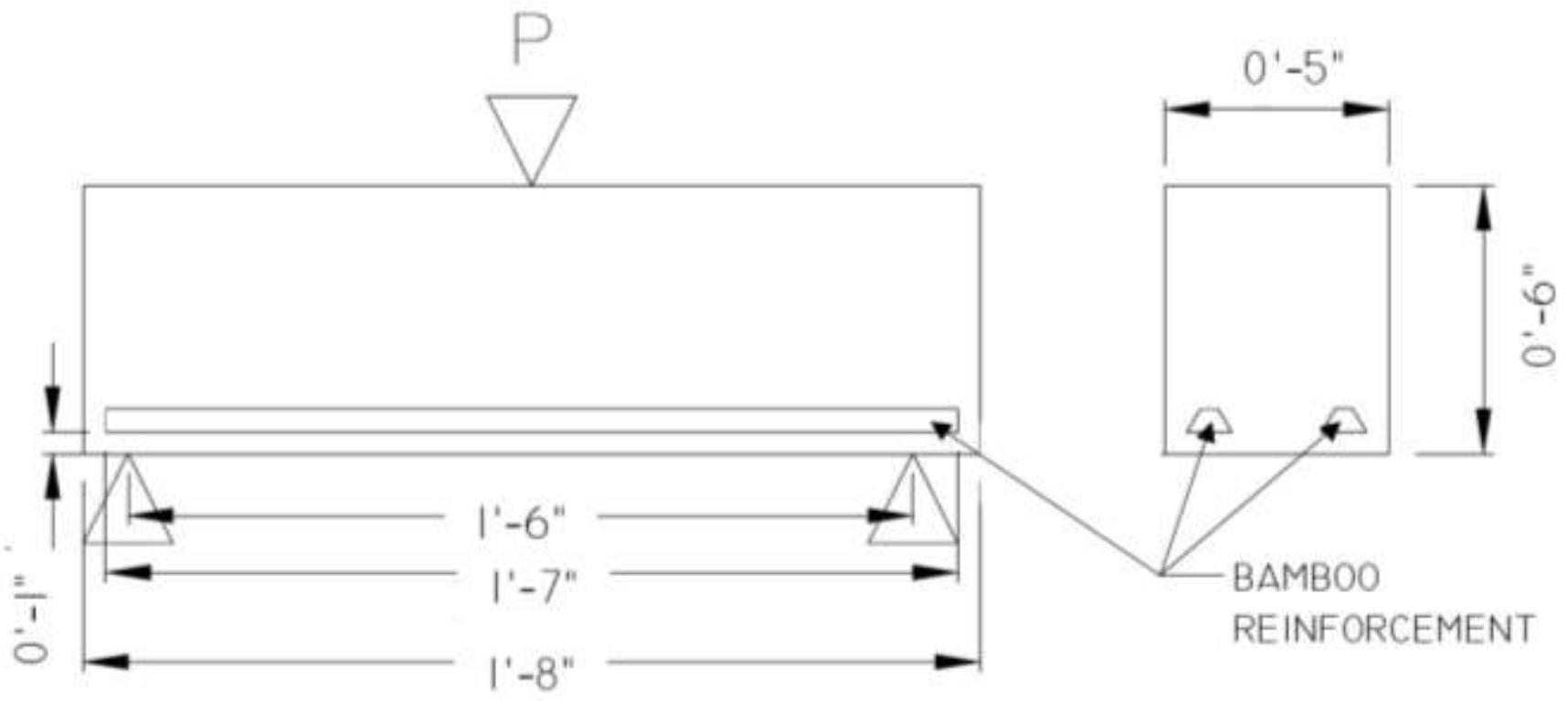

Figure 2: Dimensions of the set-up for beam samples (reinforced with bamboo strips) 


\section{Results and Calculations}

Six concrete compression tests were done and the results are shown in Table1 below. The average compressive strength of the concrete is computed to be 3,238 psf.

Table 1: Concrete compression test results

\begin{tabular}{|c|c|c|c|c|}
\hline Specimen & $\begin{array}{c}\text { Weight of } \\
\text { Specimen }(\mathrm{g})\end{array}$ & $\begin{array}{c}\text { Weight of } \\
\text { Specimen (lbs.) }\end{array}$ & Rate of load (lb/sec) & $\begin{array}{c}\text { Maximum load } \\
(\mathrm{psf})\end{array}$ \\
\hline 1 & 3845 & 8.477 & 1360 & 3480.0 \\
\hline 2 & 3890 & 8.576 & 460 & 2190.0 \\
\hline 3 & 3905 & 8.609 & 1515 & 3240.2 \\
\hline 4 & 3890 & 8.576 & 2040 & 3259.2 \\
\hline 5 & 3850 & 8.488 & 990 & 3221.6 \\
\hline 6 & 3880 & 8.554 & 2610 & 4038.0 \\
\hline
\end{tabular}

The failure loads were determined from the test results done on the Universal Testing Machines (UTM). Eq. (1) below was used to determine the nominal moment capacity, $M_{n}$ [10]. P is the failure point load applied and $\mathrm{L}$ is the distance between the supports of the beam.

$M_{n}=\frac{P L}{4}$

The distances, a, which represent the depths of the compression zones in the concrete beams were determined using Eq. (2), where $A_{b}$ is cross-sectional area of the reinforcement, $f_{b}$ is the yield strength of the reinforcement, $\mathrm{b}$ is the beam width and $f_{c}^{\prime}$ is the design concrete strength of concrete [11]. For this study, the average concrete compressive strength from the laboratory test results in Table 1 was used to estimate this value.

$a=\frac{A_{b} f_{b}}{0.85 f_{c}^{\prime} b}$

If $\mathrm{d}$ represents the depth to the reinforcement then $\mathrm{d}-a / 2$ represents the distance between the resultants of the compressive force in the concrete and the tensile force in the reinforcement. Now the nominal moment capacity, $\mathrm{M}_{\mathrm{n}}$, is given by Eq. (3) [11]:

$$
M_{n}=A_{b} f_{b}\left(d-\frac{a}{2}\right)
$$

It therefore means that the yield strength of the reinforcement, $\mathrm{f}_{\mathrm{b}}$, can be determined, such that the nominal moment capacity in Eq. (3) equates to the nominal moment capacity in Eq. (1). This was done using Solver in Excel, and the results of the computed yield strengths are shown in Table 2. 
Table 2 gives a summary of the results. Eq. (1) was used to determine the nominal moment capacity, $\mathrm{M}_{\mathrm{n}}$. The cross-sectional area for the bamboo splint reinforcement is the sum of the crosssectional areas of the two splints in each beam that is reinforced with bamboo. Eqs. (2) and (3) was used to determine the computed yield strength.

Table 2: Summary of results showing the nominal moment capacity and computed yield strength

\begin{tabular}{|l|l|l|l|l|l|l|l|l|}
\hline $\begin{array}{l}\text { Sample } \\
\text { ID }\end{array}$ & $\begin{array}{l}\text { Type of } \\
\text { Reinf. }\end{array}$ & $\begin{array}{l}\text { Reinf. } \\
\text { cross- } \\
\text { sectional } \\
\text { area } \\
\left.\text { (in }^{2}\right)\end{array}$ & $\begin{array}{l}\text { Failure } \\
\text { Load } \\
\text { (N) }\end{array}$ & $\begin{array}{l}\text { Failure } \\
\text { Load } \\
\text { (lbs.) }\end{array}$ & $\begin{array}{l}\text { Nominal } \\
\text { Moment } \\
\text { Capacity, } \\
\text { Mn }_{\text {n lbs.- }} \\
\text { ft.) }\end{array}$ & $\begin{array}{l}\text { Compute } \\
\text { d Yield } \\
\text { Strength } \\
\text { (psi) }\end{array}$ & $a$ (in.) & $\begin{array}{l}\mathrm{d}-a / 2 \\
\text { (in.) }\end{array}$ \\
\hline A1 & None & n/a & 12,300 & $2,765.1$ & $1,036.9$ & n/a & n/a & n/a \\
\hline A2 & None & n/a & 8,108 & $1,822.8$ & 683.5 & n/a & n/a & n/a \\
\hline A3 & None & n/a & 12,336 & $2,773.2$ & $1,040.0$ & n/a & n/a & n/a \\
\hline B1 & $\begin{array}{l}\text { Wire } \\
\text { Mesh }\end{array}$ & 0.029 & 14,188 & $3,189.6$ & $1,196.1$ & $\begin{array}{c}103,213 . \\
9\end{array}$ & 0.218 & 4.795 \\
\hline B2 & $\begin{array}{l}\text { Wire } \\
\text { Mesh }\end{array}$ & 0.029 & 14,114 & $3,173.0$ & $1,189.9$ & $\begin{array}{c}102,663 . \\
2\end{array}$ & 0.216 & 4.796 \\
\hline B3 & $\begin{array}{l}\text { Wire } \\
\text { Mesh }\end{array}$ & 0.029 & 14,554 & $3,271.9$ & $1,227.0$ & $\begin{array}{c}105,939 . \\
9\end{array}$ & 0.223 & 4.792 \\
\hline C1 & Bamboo & 0.51 & 13,994 & $3,146.0$ & $1,179.7$ & $6,128.6$ & 0.227 & 4.529 \\
\hline C2 & Bamboo & 0.40 & 13,162 & $2,958.9$ & $1,109.6$ & $7,271.1$ & 0.211 & 4.578 \\
\hline C3 & Bamboo & 0.42 & 14,314 & $3,217.9$ & $1,206.7$ & $7,559.9$ & 0.231 & 4.561 \\
\hline
\end{tabular}

A representation of the stress-strain curves obtained from the three-point tests done on the UTM machine are shown in Figs. 3, 4 and 5 for the samples. One for each type of reinforcement.

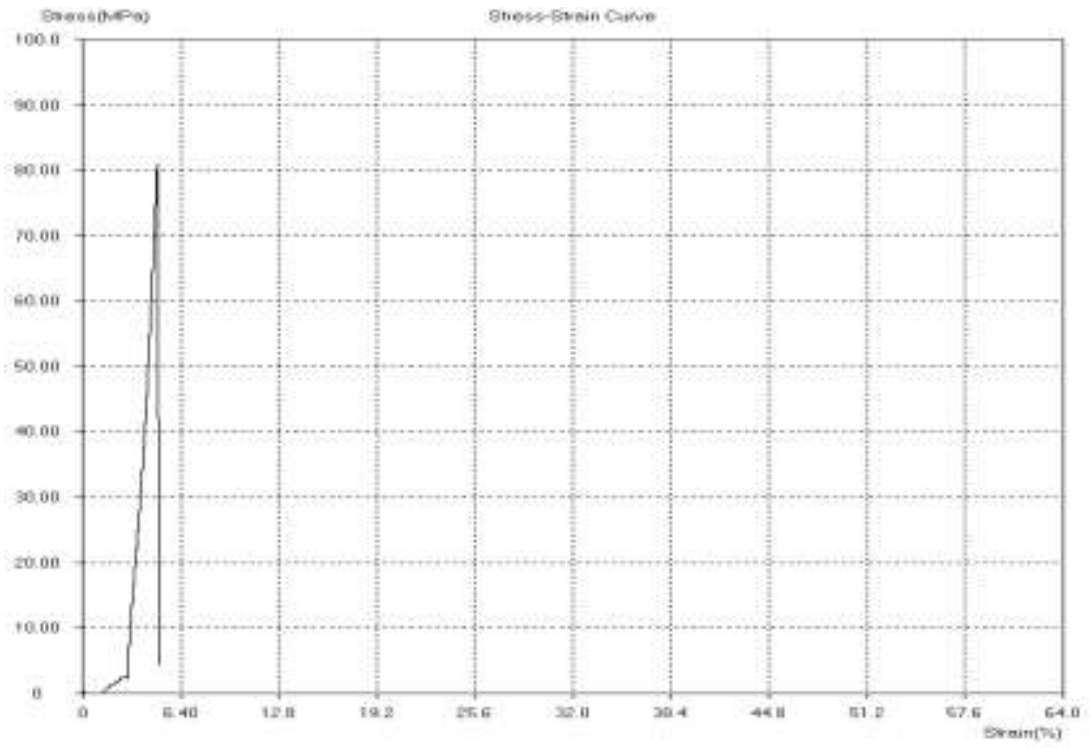

Figure 3: Showing stress vs strain of sample A3 (plain concrete) 


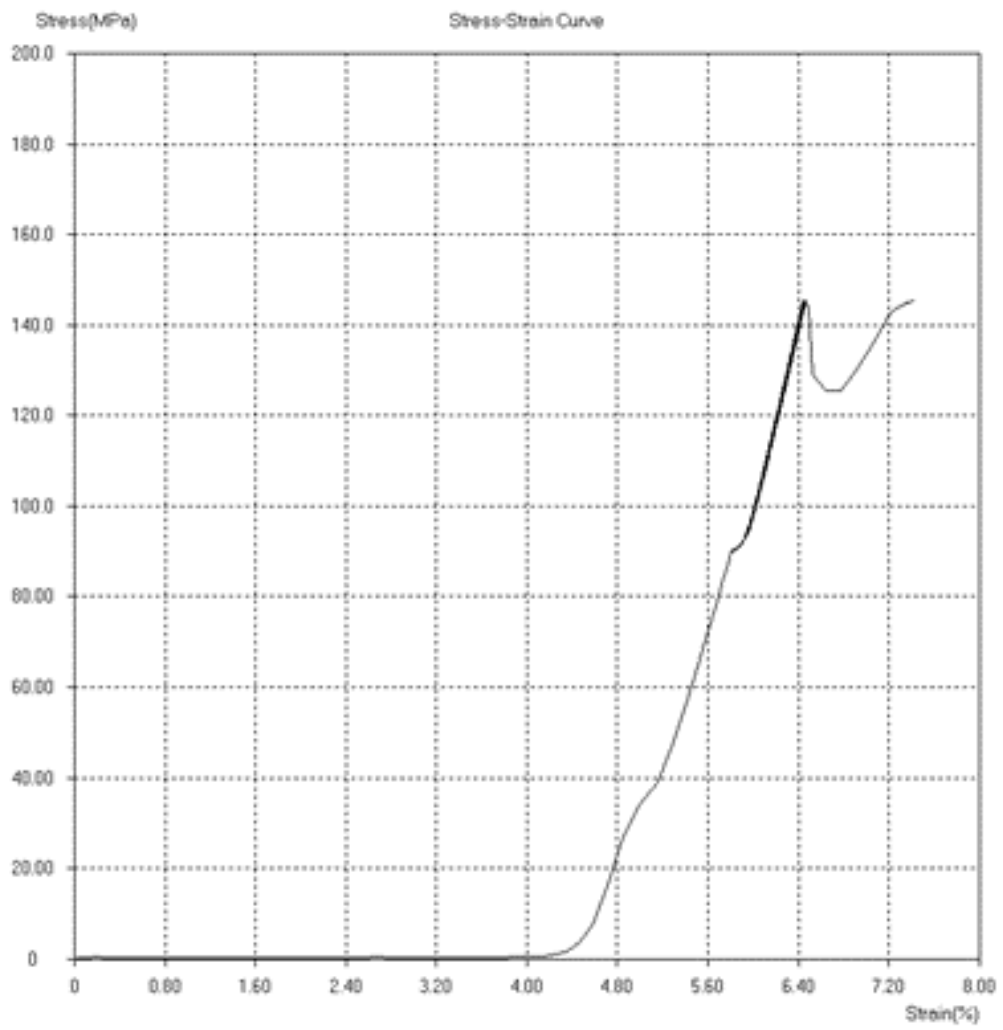

Figure 4: Showing stress vs strain of sample B1 (wire mesh reinforcement)

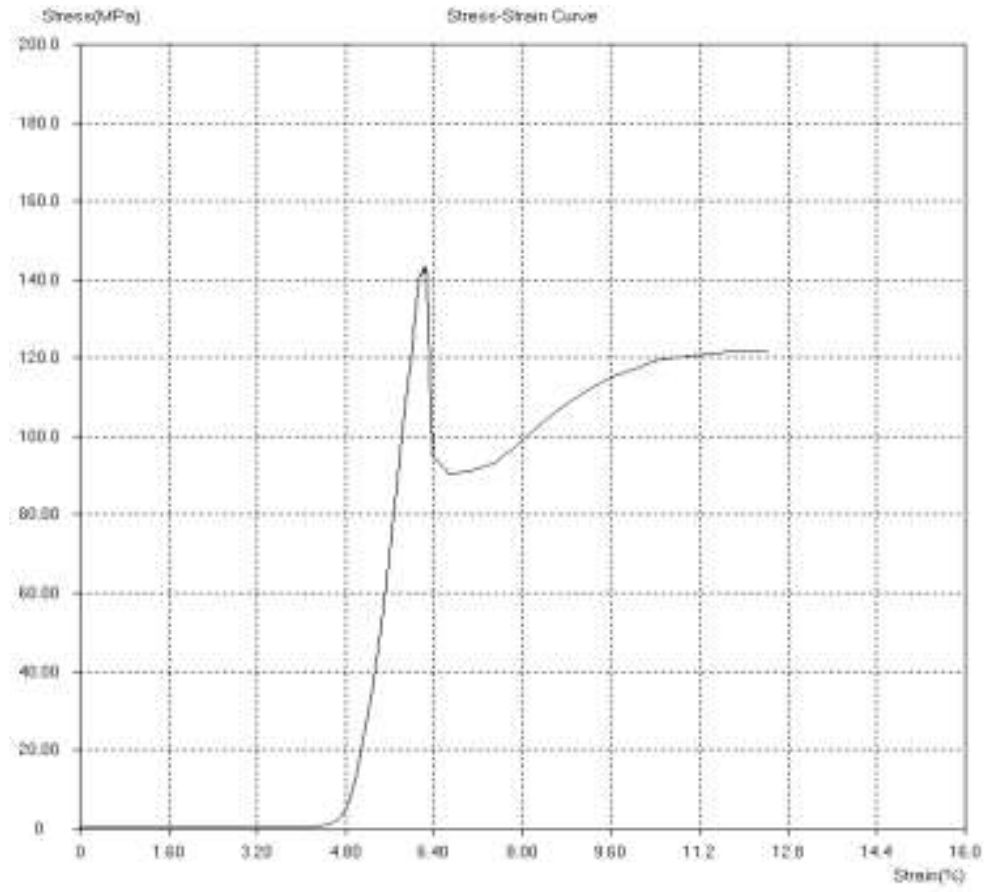

Figure 5: Showing stress vs strain of sample C2 (bamboo reinforcement) 


\section{Discussion}

From the results, it can be seen that the computed yield strength of the bamboo is notably lesser than the yield strength of the wired mesh reinforcement. Nevertheless, the bamboo reinforcement does add to the flexural strength of a concrete beam that is not reinforced. Coincidentally, the nominal moment capacities of the beams reinforced with wire mesh and bamboo were all within $10 \%$ of each other. The "spacing" of bamboo splints and the sizes of the bamboo splints were reasonable, with each beam having two (2) splints and cross-sectional areas that were not too large, having cross-sectional areas less than 0.79 inch-squared, the size of a no. 8 rebar. The yield strength is relatively low when compared against steel, as was also deduced in M.A. Ogunbiyi et al. [3]. As a result, may not be suitable for main structural elements on permanents structures. However, since the standard temporary timber structures are as the name suggests, temporary, and since currently, no reinforcement is provided in the standard concrete raft/slab on grade type foundations provided for these houses, then one can argue the use of bamboo as an inexpensive improvement to the foundation structure. Currently, many of the timber structures are outliving their foundations and so the life cycle of these temporary housing is most of the time dependent on the life time of their foundations, particularly, since the geotechnical environment for these foundations varies from location to location.

The wired mesh is a traditional type reinforcement for slab on grade structures. It prevents temperature and shrinkage cracking and thus hold the concrete together. The wired mesh type reinforcement is consistent and is predictable from design point of view and would be the preferred method for reinforcing the foundations for very light timber structures as those provided for standard housing by the FFP. However, with the increasing cost of steel and a desire to keep the cost of the FFP temporary housing at a minimal, then the use of bamboo for reinforcing the concrete foundations may be the answer. Notwithstanding there is a cost in the preparation of the bamboo for this use. This cost may be absorbed by the sweat-equity of the future owner and occupant.

\section{Conclusion}

The comparative study of the types of materials that can be used as reinforcement in concrete foundations for temporary timber house units was done. The study showed that bamboo can be used as an affordable and readily available form of reinforcement in the concrete foundation slabs for the light structures due to its tensile properties when compared with wire mesh reinforced beams. The use of bamboo reinforcement results in an increased flexural capacity when compared to an unreinforced concrete foundation slab. However due to factors such as the shrinkage and absorption rate of bamboo as compared with concrete and brittleness, proper curing methods of this organic material has to take place in order for the bonding with pure concrete to allow for greater functionality. 


\section{References}

[1] L. Jayanetti, P. Follett. Building with Sustainable Forest Products. The Structural Engineer Journal of Institution of Structural Engineer, Volume 81, Issue 1 (2003).

[2] F. E. Brink, P. J. 1966. Rush. Reinforced Concrete Construction. U.S. Naval Civil Engineering Laboratory, Port Hueneme, California.

[3] M.A. Ogunbiyi, S.O. Olawale, O.E. Tudjegbe, S.R. Akinola. Comparative Analysis of the Tensile Strength of Bamboo and Reinforcement Steel Bars as Structural Member in Construction. International Journal of Scientific \& Technology Research. Vol. 4, Issue 11 (2015).

[4] G. Lessard, A. Chouinard (editors). 1981. Bamboo Research in Asia. Proceedings of a workshop held in Singapore, 28 - 30 May 1980. Organized by the International Development Research Centre and the International Union of Forestry Research Organizations.

[5] H. Sakaray, N.V. Vamsi Krishna Togati, I.V. Ramana Reddy. Investigation on Properties of Bamboo as Reinforcing Material in Concrete. International Journal of Engineering Research and Applications (IJERA). Vol. 2, Issue 1 (2012).

[6] I.V. Ramanuja Rao, R. Gnanaharan, C.B. Sastry (editors). 1990. Bamaboos; Current Research. Proceedings of the International Bamboo Workshop held in Cochin, India from 14 - 18 Novmeber 1988. Published by The Kerala Forest Research Institute, India and International Development Research Centre, Canada.

[7] K. Ghavani. Ultimate load behaviour of bamboo-reinforced light weight concrete beams. Cement and Concrete Composites. Elsevier. Volume 17, Issue 4, (1995) Pages 281 -288.

[8] K. Ghavami, C. S. Rodrigues and S. Paciornik. Bamboo: Functionally Graded Composite Material. Asian Journal of Civil Engineering (Building and Housing). (2003) Vol. 4, No. 1. Pages $1-10$.

[9] R.A. Ruy A.Sá Ribeiro, M.G. Sá Ribeiro, K. Sankar, W.M. Kriven. Geopolymer-bamboo composite - A novel sustainable construction material. Construction and Building Materials. (2016) Vol. 123, pages $501-507$.

[10] American Institute of Steel Construction Inc. (AISC). Steel Construction Manual. Thirteenth Edition, page 3-213.

[11] George F. Limbrunner, Abi O. Aghayere. 2015. Reinforced Concrete Design $7^{\text {th }}$ Edition. Pearson Education, pages 45 - 47. 